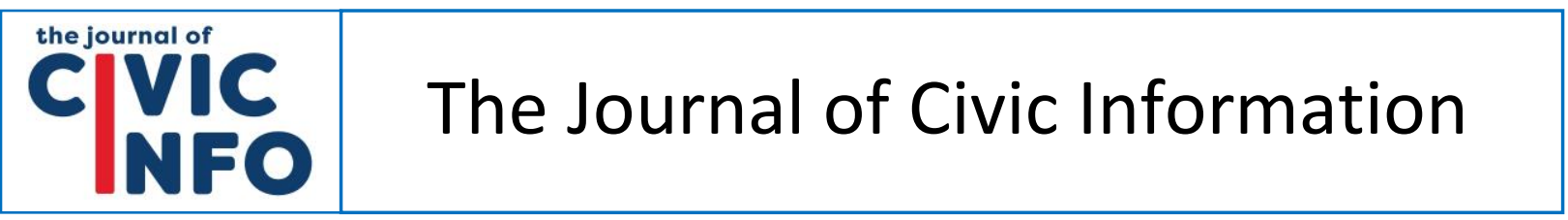

Volume 3 | Number 4

December 2021

Journal homepage: https://journals.flvc.org/civic/

ISSN (online): 2641-970X

\title{
United Kingdom Freedom of Information Act 2000, Local Government and Everyday Regimes of Practice
}

\section{Lynn Wyeth *}

Article Information

Received: Aug. 9, 2021

Accepted: Sept. 3, 2021

Published: Dec. 31, 2021

Keywords

Freedom of information Right to information Government transparency Regimes of practice

\begin{abstract}
The United Kingdom's Freedom of Information Act 2000 commenced in 2005 with the objectives of openness and transparency, accountability, better decision making and public involvement in decision making. However, there have been limited studies of its long-term impacts on government practices and how far the Act has delivered on its stated objectives, and even fewer studies into how Freedom of Information works in practice, especially at local government level. Addressing these gaps in existing knowledge, this research seeks to critically evaluate existing regimes of practices across local authorities. It seeks to identify the multiple practices surrounding the implementation of the 2000 Act, evaluate how these practices are reproduced, and generate lessons for practice and alternative modes of delivering Freedom of Information.
\end{abstract}

* Lynn Wyeth, De Montfort University. Please send correspondence about this article to Lynn Wyeth at p13065690@myemail.dmu.ac.uk. An earlier version of this work was presented at the National Freedom of Information Coalition summit FOI Research Competition, Sept. 28, 2021.

To cite this article in Bluebook: Lynn Wyeth, United Kingdom Freedom of Information Act 2000, Local Government and Everyday Regimes of Practice, 3(4) J. CIVIC INFO 40 (2021).

To cite this article in APA: Wyeth, L. (2021). United Kingdom Freedom of Information Act 2000, Local Government and Everyday Regimes of Practice. Journal of Civic Information, 3(4), 40-70.

DOI: 10.32473/joci.v3i4.130198

Published under Creative Commons License CC BY-NC, Attribution NonCommercial 4.0 International. 


\section{Introduction}

The Freedom of Information Act has been on the statute books for a little over 15 years in the United Kingdom, arguably sufficient time to identify the embedded impacts of the legislation into policy and practice (Sabatier, 2007).

A handful of studies after the initial adoption of the Act analyzed policy documents, scrutiny inquiries, and reports into the impact of the freedom of information (FOI) requests on national and local government (Holsen \& Worthy, 2010; Worthy et al., 2011; Worthy, 2013). The Constitution Unit at University College London examined how FOI affected local political leadership, local accountability, partnership working and local service provision (Amos et al., 2008). The study addressed staffing in local government, but only in terms of the numbers of staff. A study of local authorities focused primarily on the impact of the Freedom of Information Act on records management services in public authorities (Shepherd, Stevenson, \& Flinn, 2020).

Since these initial studies, little research has been carried out in the United Kingdom specific to local government, despite the large percentage of requests made to local authorities. The long-term impacts of the Act thus remain only partially evaluated and understood. This study is the first of its kind to explore and describe regimes of practice in English local government and those regimes' impact on the success of FOI practice.

Previous research has tended to focus on metrics (numbers of requests received, requests answered in time, type of requesters); the overarching aims of the legislation; or the broad impact of the Freedom of Information Act across central government and the link with transparency. There appears to be a lack of research in evaluating the regimes of practice that have come into being across local government and that answers what it is that officers do when they "do Freedom of Information" (to paraphrase Wagenaar, 2004).

This study addresses this gap in knowledge. It identifies and evaluates embedded FOI regimes of practice across English local authorities, exploring how these have come into being, how they have evolved and been reproduced. In so doing, it seeks to characterize the political (both with a capital $\mathrm{P}$ and a smaller $\mathrm{p}$ ) reasons of these regimes, engaging with their dynamics to draw lessons that contribute to the improvement of practice.

In order to identify the multiple practices surrounding the implementation of the 2000 Act, this study explores the particular community of practice of FOI officers, engaging initially via fora/mailing lists and email, and then through semi-qualitative recorded interviews to hear their experiences and to understand how and why they have adopted the regime of practice that they have, if these regimes of practice result in effective management of the FOI legislation, and how management practices have developed in response to the challenges they faced in adopting new legislation and current budget constraints and priorities in local government. The findings provide lessons for the practice and alternative modes of delivering FOI, and the influence of policy making.

History of the United Kingdom's Freedom of Information law

During the 89 years between the adoption of the Official Secrets Act 1911 and the Freedom of Information Act 2000, the United Kingdom government reluctantly incrementally increased access to information under political pressure, often at election times. Similarly evolving in parallel was an international backdrop that was also influential during this passage of time.

The Fulton Commission launched in 1965 to examine the structure and management of the 
civil service (Committee on the Civil Service, 1968). The Fulton Report proposed that an investigation be undertaken into eliminating unnecessary government secrecy. The report was critical of the civil service in many ways, and made numerous recommendations to modernize the officialdom so that it was fit for the $20^{\text {th }}$ century. The report acknowledged the need for safe space for officials and politicians to discuss policy making freely, but also the public interest in decisionmaking, thus setting out some of the cornerstones of the Freedom of Information Act that was eventually passed into UK legislation.

The following year, in response to the report, Prime Minister Harold Wilson introduced a 30-year rule on the release of records, in the Public Records Act (1967), reducing it from 50 years. Despite a change of government in 1970, the issue was now on the public agenda. This was not welcomed by the then Conservative government and this reform would take until 1989 to be implemented.

In 1972, new legislation allowed public access to meetings and some documents of specific national committees (Local Government Act, 1972). The Labour Party promised in their 1974 manifesto to introduce some form of a Freedom of Information Act, which promised to "replace the Official Secrets Act by a measure to put the burden on the public authorities to justify withholding information" (Labour Party, 1974).

Home Secretary Roy Jenkins in 1975 undertook a visit to the United States to look at the Freedom of Information law in place there, adopted in 1966. The United Kingdom Freedom of Information Act, once eventually enacted, would look quite different to the U.S. version, and its big difference was that in the United Kingdom, it would apply to all public sector organizations in exactly the same way. U.S. FOIA applies just to the federal government, and local jurisdictions are subject to each state's public records law.

The appointment of Margaret Thatcher as Prime Minister in 1979 meant further frustration for supporters of transparency, as despite her previous desire to increase openness in local government, Thatcher was not interested in similar concessions at a national level. In response, January 1984 saw the launch of The Campaign for Freedom of Information in the U.K., founded by Des Wilson. The Campaign for Freedom of Information initially had the support of the leaders of the three main opposition parties and over 150 cross-party Members of Parliament (Secrets Newspaper, 1984).

Members of Parliament continued to force the issue via repeated Private Members Bills; Frank Holey of the Labour Party in 1981 and David Steel of the Liberal Party in 1984. In response to increasingly visible pressure in Parliament and by public campaigners, Thatcher paid lip service to openness with the introduction of The Data Protection Act 1984 and expansion of the Local Government Act in 1985. Local government had concerns that the Local Government (Access to Information) Act 1985 would cause administrative burden and resource implications (Lister, 1988). Awareness of rights under the Act was, on the whole, found to be extremely low among the members of the local press, but many still benefited from the Act's rights by receiving copies of committee papers and attending certain meetings of the Council or its committee, as still happens today (Steele, 1995).

Thanks to developments in the European Union there came a breakthrough in 1992 with the introduction of the first Environmental Information Regulations (1992), which allowed access to some environmental information, although they were not well publicized.

Des Wilson, Maurice Frankel and the Campaign for Freedom of Information continued to put pressure on the Government via the press. In April 1994, an article was published in the Observer supplement on Censorship entitled Addicted to Secrecy, Lies and Distortion, in which 
Frankel posed the question "If secrecy is the British disease, is it curable? Over recent decades many classic secrecy battles have been fought - yet the same issues remain sources of conflict." (Campaign for Freedom of Information, 1994).

Both the Labour Party and the Liberal Democrat Party promised a Freedom of Information Act as part of their 1997 manifestos. Tony Blair appeared supportive of the idea, and whilst presenting awards at the Campaign for Freedom of Information's annual Awards ceremony on 25th March 1996 said:

"Our commitment to a Freedom of Information Act is clear, and I reaffirm it here tonight. We want to end the obsessive and unnecessary secrecy which surrounds government activity and make government information available to the public unless there are good reasons not to do so. So, the presumption is that information should be, rather than should not be, released. In fact, we want to open up the quango state and the appointed bodies, which will of course exist under any government, but which should operate in a manner which exposes their actions to proper public scrutiny.” (Campaign for Freedom of Information, 1996) ${ }^{1}$

The election of Tony Blair's Labour Party in 1997, with a considerable majority, gave hope to freedom of information campaigners in the United Kingdom that an Act would be adopted at last. Instead of publishing a bill however, the new government chose to publish a white paper, which was delayed until December of 1997 (Your Right to Know, 1997).

In 2001, the Campaign for Freedom of Information issued a press release berating the fouryear delay in implementing the Freedom of Information Act, as totally unjustifiable (Campaign for Freedom of Information, 2001). The United Kingdom Freedom of Information Act finally became law on January 1, 2005. From the very first year, local authorities were in receipt of the majority of FOI requests.

\section{FOl at the local level}

There are 343 local authorities (also known as councils) in England. They vary in type and have different responsibilities. Metropolitan districts, London boroughs, and unitary authorities undertake all local services for their citizens. County councils are an upper tier authority and undertake services such as education, social care, and transport, whereas district councils (sometimes also called borough councils) are lower tier authorities and provide services such as housing and waste management. Metropolitan districts, London boroughs, and unitary authorities, covering all services, can receive many requests, as do county councils, who despite offering fewer services, serve many more people in their geographical area. District councils, although still receiving many requests, are often much smaller in size and numbers of staff, presenting resourcing issues. The make-up of local authorities in England is as follows:

- Metropolitan districts (36)

- London boroughs (32) plus the City of London

\footnotetext{
${ }^{1}$ After Blair left office, he had a far different perspective of public and press access to government records, according to his memoir (2010): "Freedom of Information Act. Three harmless words. I look at those words as I write them, and feel like shaking my head 'til it drops off. You idiot. You naive, foolish, irresponsible nincompoop. There is really no description of stupidity, no matter how vivid, that is adequate. I quake at the imbecility of it."
} 
- Unitary authorities (55) plus the Isles of Scilly

- County councils (26)

- District councils (192)

Research by mySociety ${ }^{2}$ indicates that a substantial $63 \%$ of FOI requests in the United Kingdom are submitted to local governmental agencies (mySociety, 2021). The research estimates that approximately 468,780 Freedom of Information requests were sent to local government in 2017, including England, Wales, and Northern Ireland. Scotland has its own Freedom of Information (Scotland) Act 2002. By 2017, numbers of requests to local government dwarfed any other public authority sector. As the mySociety reports states:

Based on the data collected for this report, the estimate for English councils only, is 388,736 FOI Requests in 2017. This represents a $97 \%$ increase on the 2010 figure of 197,000 estimated by the Constitution Unit. In the same period FOI Requests sent to audited central government only increased by $6 \%$. Whether this represents a historical under-count or a growth over time (10\% a year), the current volume of FOI is nearly double the previously available estimate.

Using previous data from the Constitution Unit (2011) and this new research, mySociety estimates that over 300,000 requests are sent every year to English councils.

Despite the millions of FOI requests that have been submitted to local authorities since 2005, throughout the last 15 years there has been little data produced centrally on the performance of public authorities at local authority level. This is in contrast to central government where departments have been required to publish performance statistics online (https://www.gov.uk/government/collections/government-foi-statistics).

The Cabinet Office has responsibility for Freedom of Information policy in England, Wales, and Northern Ireland, and publishes information on the handling of requests by individual government departments quarterly. Freedom of Information statistics are designated National Statistics in accordance with the Statistics and Registration Service Act 2007. Performance data is available online from 2010 showing numbers of requests received by central government departmental breakdown, how many were answered, how many were answered within the legal timeframe, whether information was released and which exemptions applied if the information was withheld.

In contrast, local authorities in England, until 2018, were under no obligation to proactively report on their performance under the FOI legislation. The only way to establish comparable datasets is to submit a FOI request to several hundred local authorities. Not all authorities record all of the data. This reflects similar issues in other countries such as the United States, where the 50 states, the District of Columbia, and territories all have their own public access laws that can be consulted for access to state and local records (as opposed to the national U.S. FOIA statute, which applies only to federal agencies). Whilst websites provide links to all of the 50 states and

\footnotetext{
${ }^{2}$ The United Kingdom nonprofit organization mySociety tracks how many FOI requests are made to local government each year. The group works with partners internationally to build and share digital technologies that help people be active citizens, using software by Alaveteli (https://alaveteli.org/). Alaveteli has helped citizens make over 800,000 requests in 25 jurisdictions. In the United Kingdom, mySociety runs and promotes the website www.whatdotheyknow.com, an online tool that allows the public to easily make FOI requests to all public sector organizations covered by the Act. Similar sites are available in other countries such as AccessInfo in Hong Kong (https://accessinfo.hk) or MuckRock (www.muckrock.com) in the United States.
} 
the District of Columbia, and many states are now developing state-level open data portals, there is still a dearth of centrally collated data to compare FOI performance across states, giving a very similar situation to the United Kingdom's inability to compare performance at local or state levels, other than in Scotland (Scottish Information Commissioner, 2021).

Ten years after the implementation of the Freedom of Information Act, The United Kingdom's Cabinet Office established the Independent Commission on Freedom of Information. The Commission was tasked with evaluating how well the Act was operating. It determined that in the main the Act was operating well, but did make 21 recommendations to further the original aims of the legislation (Independent Commission, 2017). As a result of these recommendations, the Cabinet Office proceeded to undertake a consultation exercise on updating the section 45 Code of Practice. This code provides guidance to public authorities on the discharge of their functions and responsibilities under Part I (Access to information held by public authorities) of the Freedom of Information Act. The review resulted in an update to the code, which mandated many more public authorities to proactively report their FOI compliance:

The government agreed to implement the Commission's recommendation that public authorities with over 100 full time equivalent employees should publish statistics on the operation of the FOI Act. Central government departments already publish these statistics on a quarterly and annual basis, but it is important that other public authorities achieve a similar level of transparency. The publication of this data will provide greater accountability to both the public and the Information Commissioner. (Information Commission, 2017, p. 9)

The revised section 45 Code of Practice, therefore requires all local authorities to publish performance statistics, but not in the same details as central government. The Cabinet Office justified this as not wanting to place a burden on smaller public authorities. The revised code requires that:

Public authorities with over 100 Full Time Equivalent (FTE) employees should, as a matter of best practice, publish details of their performance on handling requests for information under the Act. The information should include:

- The number of requests received during the period;

- The number of the received requests that have not yet been processed (you may also wish to show how many of these outstanding requests have extended deadlines or a stopped clock, e.g. because a fee notice has been issued);

- The number of the received requests that were processed in full (including numbers for those that were met within the statutory deadline, those where the deadline was extended and those where the processing took longer than the statutory deadline);

- The number of requests where the information was granted in full;

- The number of requests where the information was refused in full (you may wish to separately identify those where this was because the information was not held); 
- The number of requests where the information was granted in part and refused in part;

- The number of requests received that have been referred for internal review (this needs only reporting annually).

It is for individual public authorities to decide whether they wish to publish more detailed information than that set out above (they may, for example, wish to show a breakdown of the exemptions they have used for refusing requests or to show a breakdown of the outcomes for their internal reviews). When public authorities publish their statistics, they should do so on a quarterly basis, in line with central government." (Information Commission, 2018, p. 29)

Three years on and many public authorities, including local authorities, are still not complying with this requirement. Further research is required to identify the barriers, but this could be through lack of awareness of the requirements (there has been no central notification from the United Kingdom government to other public sector organizations about a change in FOI legislation or Code of Practice updates).

There is also no requirement for the data to be deposited centrally with the United Kingdom government or the national regulator for Freedom of Information, the Information Commissioner. Where local authorities do publish data, there is no fixed or comparable format, and the datasets are not always updated regularly.

With so little data available, how can taxpayers be confident that the hundreds of local authorities are meeting their compliance requirements under the Freedom of Information Act 2000 ? How do they know which local authorities are performing poorly other than those appearing in media stories or the Information Commissioner's enforcement listings? This study attempts to answer those questions.

\section{Methodology}

In order to meet the aims of the study, it was decided to adopt a qualitative research and interpretive approach. This was a choice to explore the decision-making processes and to identify and explore FOI officers' actions. Semi-structured interviews were considered to be the most appropriate method for exploring these aims.

\section{Interview selection and process}

The research consisted of interviews with 17 FOI officers from different English local authorities. Study participants that were selected included local authority officers who appeared to be employed in teams that may be processing FOI requests on a regular basis. Freedom of Information often sits within the area of work termed "Information Governance" in the United Kingdom and this can include the field of data protection as well as FOI. In order to widen the scope to reach local government officers engaged in FOI, information governance, data protection and FOI staff were included.

Information governance and FOI officers were identified through those officers posting publicly online in FOI communities of practice, and national mailing lists and fora, including relevant information governance mailing lists on the academic mailing list resource, 
Jiscmail.ac.uk, and relevant information governance groups on the collaboration website Knowledge Hub, www.khub.net. The sampling strategy assumed that that these officers were most likely to be engaged in debates about FOI, and are actively engaged in communities of practice. The most recent two years' worth of interventions on the above name fora were analyzed to identify those FOI officers to initiate contact with, choosing a range of contributors from sporadic to persistent and those that appeared to be still in post and whose contact details were readily available in the public domain.

A variety of different councils were approached, including county, unitary, borough, and metropolitan in order to obtain a range of councils of varying sizes. Some authorities who are seen in the sector as promoting good practice via posts on the mailing list were approached, as were those that have had coverage for weaker compliance (via media stories or the Information Commissioner's Office interventions in poor performing authorities). One of the limitations in the research to date is that the poorer performing local authorities were less inclined to take part in the research.

The researcher is herself an experienced FOI officer and was conscious of her own anecdotal experiences, previous connections with other FOI officers and potential bias whilst obtaining the participants and conducting the interviews.

Recruitment of the study participants took place in October, 2020, and 32 potential study participants were contacted. Initial concerns that the impact of the COVID-19 pandemic may result in reduced participation was partially unfounded. Despite pressure on local authorities during the pandemic, a sufficient number of information governance officers who were contacted found time to engage in the study, with more than half of those contacted responding positively. More would have engaged in the project if it had not been for COVID-19 impacting disproportionately on local authorities. Local authorities were at the forefront of the response to COVID-19 in England, with many staff redeployed onto unusual duties such as running food banks, administering emergency grants (personal and business), and running COVID-19 testing centers. The researcher herself was redeployed to deliver door-to-door COVID-19 tests to residents at the height of the prolonged lockdown in her city. Several of the candidates who were approached declined to take part, indicating that they would have liked to have participated but simply did not have the time due to the priorities of their local authority during the pandemic.

Seventeen agreed to participate in the study and all interviews were carried out in November, 2020 (see general descriptions of each participant in Appendix A). Interviews were conducted online over Microsoft Teams and lasted between 30-60 minutes, with the majority lasting the full hour. The transcripts were coded using NVivo software. Using thematic analysis as an iterative process, preliminary codes were attributed and common themes were established (see Appendix B for coding terms).

\section{Question topics}

The findings from the interviews undertaken with the FOI practitioners were split into two areas of focus, first on structure and process, and secondly the spaces of agency.

The first area of focus, on structure and process, included a focus on job titles, employment backgrounds, experience, location within an organization, resources provided to carry out the work, staff support, workload, and technological tools. 
The second area of focus, on spaces of agency, examining the power of FOI officers to assess the risk of requests, monitor performance, apply exemptions, ensure quality, handle sensitive requests, and become involved in policy change.

\section{Findings}

After synthesizing the interviews, common themes were clustered into the two main areas: 1) Structure and process and 2) Spaces of agency. Actual quotations are provided to illustrate the key findings.

Structure and process

\section{Staff and job titles}

From speaking with the study participants, it is clear that there is not a conventional and universally recognized title for the officer responsible for responding to FOI requests within a local authority. From the 17 interviews conducted, the participants had a total of 13 different job titles as follows:

- Information Officer

- Data Protection Officer x 2

- Data Protection Officer and Corporate Information Governance Officer

- Information Governance Manager x 3

- Information Governance Officer x 2

- Data Protection Officer and Corporate Compliance Manager

- Information Governance Lawyer

- Information and Records Manager

- Information Governance Manager and Data Protection Officer

- Freelance FOI consultant

- Senior Complaints Practitioner

- Senior Information Officer

- Information Governance \& Risk Manager

It is striking that not one of the job titles other than the freelance consultant has "freedom of information" in the title. All roles involve work other than FOI, many with an equal or larger focus on data protection, or the role is merged with complaints, information management, risk management, or records management. The mySociety report into local government discovered that "based on the survey of FOI officers, most respondents (93.4\%) reported that they had freedom of information as a primary responsibility, with data protection also being a significant responsibility for most (67.6\%)" (Parsons \& Rumbul, 2019, p. 7). Freedom of information appears not to be given any prominence in the job titles of those custodians trusted to ensure the local authority is compliant with the Freedom of Information Act.

\section{Employment backgrounds}


Identified from the interviews was the different professional backgrounds that local government officers undertaking FOI tasks originated from. This gives insight into the knowledge and skills they held before acquiring the role. Historical employment experience included a wide variety of professions including two of the study participants previously working in libraries. Others included a government civil servant who specialized in IT and cyber security, a school administrator, a secretary, a solicitor with previous family law experience, and a tree surgeon. Transferable skills rather than FOI knowledge appears to be key.

The participants' career progress into the field of FOI can be categorized into three different areas. The first area is those staff who were existing local authority or government employees who were subject to redeployment and had recognizable transferable skills or some basic knowledge of information governance, for example, data protection in their role, or they were returning from maternity leave or retirement and required a role in the same authority offering reduced hours of working and no evening work. Despite the statutory deadlines and firefighting required by the FOI legislation, organizations see it as a 9-to-5 Monday-to-Friday job.

Second, some study participants were relocating geographically and were looking for anything in the area that they had transferable skills for. These participants did not necessarily have any previous FOI knowledge or experience.

Third, and quite commonly, the FOI role was appended onto an existing role in a) 2005 when the Freedom of Information Act came into force or b) in an internal organizational restructure within the local authority, or c) existing staff left the authority. Freedom of Information officers repeatedly spoke of "being dumped with it" or it "being tagged onto their job." One said:

"Our person in our legal team who was dealing with data protection, I think, was preparing to retire and they wanted to pass it on and I was the lucky, or unlucky person, who ended up with it."

Jobs included those not advertised as an FOI officer role, but incorporated that work or grew to include it. Participants talked about the following situations:

"No Freedom of Information experience and they didn't really know what they were looking for. Freedom of Information creeped in to the job."

"Started off as records officer, quickly was given Freedom of Information and policies to look at."

"Formerly a complaints manager. Freedom of Information was tagged on."

"I took a role...working as what was then called a programmes assistant but essentially my role was dealing with Freedom of Information requests."

From the interviews undertaken it appears that there is no clear professional employment route into the role of FOI officer.

\section{Experience and qualifications}


The lack of knowledge about FOI in 2005 could, of course, be understood as it was new legislation, but it appears that jobs advertised more recently are still not requiring applicants to have that experience or knowledge. Participants gave the following examples:

"I knew nothing about Freedom of Information. I had to Google it before I went for my interview."

"Legal background but no FoI experience."

"Previously in Revenues and Benefits, potential reduction of funding, redeployed internal application in 2014. Bit of knowledge of data protection, no Freedom of Information."

"Had previously had to answer some requests and heard of it but not the details of Freedom of Information."

Local authorities appear to have rarely asked that prospective candidates for FOI employment roles have experience in that area as an essential requirement, with it often only being a desirable criterium, if mentioned at all. As well as previous experience not being essential, a legal background is not required despite the role interpreting complex legislation on a daily basis. It appears to be seen by many as an administrative back-office type function, as opposed to a statutory frontline service interpreting complex legislation and case law. It is often allocated to lower paid administrative staff or complaints officers due to the nature of the procedures involved, as opposed to acknowledging that it is a frontline statutory highly skilled profession.

Despite the recognition by those who work in the field that FOI officers do actually require many different skills, as well as knowledge of the law, there appears to have been no real professionalization since 2005. This is unlike data protection work that now sees the statutory post of the Data Protection Officer and the requirement of expertise enshrined in the United Kingdom General Data Protection Regulation and Data Protection Act 2018.

It is also notable there has been no national apprenticeship for the FOI role to date. Apprentices have had to undertake general administration/business studies or public sector apprenticeship, which does not enable the apprentice to demonstrate the skills and knowledge they have gained in relation to the FOI legislation. An information governance apprenticeship is being developed nationally, driven by former and current information governance officers.

There is little planned career progression, and often no succession planning within authorities. There is evidence that some officers move from FOI officer to senior FOI officer to FOI manager. Other officers move from district councils to county councils, which is seen as a promotion due to the size of the local authority. There appears to be little route to progress higher within the authority once one has become manager or head of the information governance service, and long-serving FOI officers and managers do not often progress to become heads of service and there is no evidence they become service directors.

There are very few nationally recognized qualifications specifically for FOI officers. Various training companies delivering training to the information governance sector have developed four-day FOI practitioners' certificates but there is nothing formally recognized by the Information Commissioner's Office to date. Freedom of Information officers wishing to continue 
their professional development seek out such training courses and other daylong courses themselves and some even self-fund such training.

\section{Location within the organization}

It was clear from the job title evidence that there was not a conventional and universally recognized title for a local authority officer undertaking the FOI officer role. Similarly, when the study participants were asked which department or division of the local authority the FOI function was located in, a similar pattern appeared. From the 16 interviews conducted with study participants that currently worked in a local authority, the 11 different directorates or divisions that hosted the FOI function were as follows:

- Legal Services x 6

- Corporate Services

- Information Technology

- Customer Services

- Resources

- Strategy and Communication

- Legal and Democratic Services

- Governance \& Risk

- Chief Executive's

- Legal and Governance

- Corporate Governance

Legal Services, Legal and Democratic Services, Governance \& Risk, Legal and Governance, and Corporate Governance, can all be brought under one umbrella showing 10 of the 17 study participants see their FOI functions positioned in the Legal/Governance arena.

From the study participants' further context, there is evidence that the FOI function has been regularly moved within local authorities from one department to another or should be moved as follows:

"Information Governance Lawyer in Customer Services feels that it should sit in Legal Services."

"Currently in the Resources Dept, but it has moved around, previously it was hosted by the Assistant Chief Executive's Office."

"It moved to internal audit and then we had to restructure and it came back to Legal Services."

"Now in in Strategy and Communication, it was once in Legal Services. Multiple hats in a small council give strange bedfellows."

“...in Governance \& Risk under Chief Finance Officer. It was previously in Legal Services and will be moving back to Legal Services." 
"Weirdly, Freedom of Information was originally, I think, contained within the elections team."

The FOI role itself was often seen as an add-on to existing roles, and similarly the positioning of FOI function in the local authority has seen it added in to an existing department without ever completely fitting in and having a true and obvious home of its own. After 15 years, local authorities are still moving it from one department or service to another.

From the study participants interviewed, there is evidence that the FOI function is now more commonly finding its place positioned in the Legal Services/Governance divisions within local authorities in England, possibly indicating that it is beginning to have more purchase when located there and there is a growing realization about the legal expertise needed. This insight from a study participant noted the relevance of where the role was positioned:

"I think I probably have less autonomy in the job I have here than I did when I worked for the County Council and I think that comes from being sat within Legal Services, previously we weren't part of Legal Services. Each individual service department has their own team that dealt with FOIs and I think being part of Legal brings a bit of a different viewpoint because obviously my manager is a legal professional and perhaps has a different eye on how things are done, and I think sometimes that's quite good because it means they try and follow things according to the legislation rather than trying perhaps to get round things that people with less knowledge of FOI might have."

\section{Resources}

The study participants were asked if they believed that there was sufficient resource (e.g., numbers of staff, appropriate IT systems) to manage the FOI function adequately. Responses were mixed, with half of the respondents relatively satisfied that resourcing was usually adequate in normal circumstances (pre-COVID-19). Half of the participants expressed concerns about the levels of adequacy of resourcing. The lack of staffing resource was the issue raised the greatest number of times. This was predominantly within the smaller borough and district councils. Many of these smaller authorities only allocated one officer to undertake the day-to-day processing of Freedom of Information requests. On occasions, this was supplemented by limited administrative support, but this support was often a non-specialist on FOI.

\section{Lack of staff}

The majority of study participants that cited staffing resource as an issue said that they needed extra staff to aid them in answering FOI requests. A recurring theme was that these needed to be permanent staff. There was evidence that vacant posts were not filled, or were not filled permanently with the following comments made:

"There was one and a half information officers, which was held by three part time people, and they all left. The latest half time has left too. They were going to get an admin role, and that's not been replaced." 
"We couldn't cope with the workload, so they have now appointed, on a temporary six-month basis, a replacement information officer."

"I would like more resource and like permanent resource."

"I could have really done with just another full-time member of staff quite frankly, and there wasn't the budget for it, so I just got on with it then. But you just do, don't you?"

"It just became a very, very poor second-class citizen because of GDPR... they needed a second member of staff."

\section{Support staff}

Study participants spoke of the challenges of a lack of administrative support if they, solely, had to process FOI requests. Where some administrative support was in place, a theme emerged around the fact that this support was not necessarily knowledgeable about FOI legislation. Some management teams in authorities saw it as simply a process, similar to the logging of any service request and complaint that could be handled by any administration assistant or clerk, many on low levels of pay. One study participant said:

"I don't think they are appropriately trained or appropriately qualified, knowledgeable, experienced individuals and nobody's asking them for it, they will just move somebody from general customer service."

Another study participant said they wanted their support staff to have "more insight than just logging them" (the requests).

Study participants also acknowledged that this lack of knowledge in other staff led to additional negative outcomes longer term such as succession planning, with one stating:

"I am conscious that there's no one really in the organization with anything like the experience and knowledge that I've got so I'm aware of the succession planning."

\section{Workload}

Several study participants raised the issue of being unable to cope with the demands of the role due to the heavy workloads. As discussed earlier in this article, local government receives the most amount of FOI requests by sector by far (63\%). Even the smaller borough and district councils receive hundreds of requests every year, with unitary and county councils averaging over 1,000 per year, and some can receive anything up to 2,000 requests. The number of requests to local government has increased year on year.

Despite this increase, there is no evidence from this study to demonstrate that resources have increased in order to manage the increase in demand. Local authorities have never been awarded ring-fenced funding from central government in order to meet this statutory requirement. Study participants said: 
"We have the same number of staff now as when we started...in that first year we had 250 requests... will be around 2,000 this year plus all the other services that we have provided."

"We can't cope with the number of requests that we're getting."

Study participants also raised the concern that this under-resourcing of staffing levels required lead to a negative impact on performance when any staff were on leave or away due to sickness.

\section{Covering of leave}

In those local authorities where study participants said there was only one key member of staff responding to FOI requests, it appears that there are pressures when that individual is absent for work.

"We have small team. It's one full time officer whose primary role is receiving, distributing, logging, and responding to FOIs. I support the officer when they are absent."

"If I'm on leave, nobody does anything, so no requests get logged."

From the above quotes it can be seen that this absence is dealt with differently by those two authorities. One tried to cover it, pulling in a more senior officer who normally focusses on data protection to temporary cover, but expecting that member of staff to effectively carry out two jobs at once. Similarly, another study participant said "there's one person and then it's just a member of another team will step in while they're on leave." The second example shows that some authorities will not log any requests and deal with them until the FOI officer returns running the risk of non-compliance with the requirements of the Act.

\section{IT systems}

All study participants worked in local authorities that had some type of logging system in order to capture and monitor the FOI requests it received. This ranged from a simple Excel spreadsheet to a specially procured FOI-friendly customer relationship management system. The majority of local authorities taking part in the study had, however, not procured a specialist FOI logging system, many of which appear to be prohibitively expensive in the current financial climate. The authorities that had procured a customer relationship management system had done so for another service and adapted it to also record FOI requests. Systems discussed that fall under this category included IKEN (usually used in legal services case management), InCase Intelligence (usually used in fraud case management), Respond and Civica Icasework (both usually used in complaints case management). This results in a system that is not completely fit for purpose and cannot offer all of the benefits as a bespoke FOI system can to enable officers to save time. In use by the study participants were:

Excel control sheets x 3 
Internally developed bespoke system x 3

CycFreedom *

ECase *

Civica Icasework x 2

Respond $\mathrm{x} 2$

Firmstep x 2

IKEN

InCase Intelligence (FOI module)

\section{* Specialist Freedom of Information case management systems}

One study participant said that "sometimes they throw officer time at it and not technology" and he was particularly supportive of the need for a system to support the FOI officer. One study participant, who had procured a specialist FOI system said, "I honestly don't know how organizations run without one." Some of the study participants worked in local authorities that had recently procured systems to help them. In contrast, one authority will be removing its logging system due to budgetary constraints, saying:

"We're looking to change from this database to just using spreadsheets due to financial pressures on the local authority."

Spaces of agency

\section{Managerialism}

The decisions made personally by the FOI officer with no other input from any senior officer in the authority can have a dramatic impact on the effectiveness of the FOI function in a local authority, although they themselves rarely acknowledge it in those terms. From the study participants, several themes emerged which demonstrate that the FOI officers were making independent decisions outside of basic administration tasks in order to achieve positive results for the requesters and minimize risk of enforcement action for their organization.

\section{Assigning of requests}

Local authorities are made up of hundreds of different services, staffed by thousands of officers. The FOI officer has to learn where to send all of the many different requests quickly so as not to lose time by sending them to the wrong service areas. Many of the study participants have developed "cheat sheets" or databases over the years listing which officers in their authority deal with specific types of information and requests, for example:

"I then assign it to the relevant department, so I will work out who in the authority will potentially hold the information."

"We have a list of coordinators and a list of sign off managers." 
"We've got a lead officers in every business area, so we would then assign the request to as many different areas as we think are appropriate... from their knowledge of the organization, they would determine who they think holds the information. You can search for cases so you could search by topic to see who that request was assigned to before."

"We have a document spreadsheet. It's a living document. It gets updated as and when it's needed, but essentially it's been built up since I think we started it.... You're constantly updating it. We constantly remove stuff because teams no longer exist or you have been reformed and do a slightly different thing, but essentially we call it our requests library."

The FOI officer also decides what to inform the service area. The FOI officer makes the decision to tell them who the request has been received from or not, and if in his or her opinion it is deemed a sensitive, high risk or controversial request. They may decide to reveal it is from the media, and may decide to escalate to senior managers or politicians if it is deemed sensitive.

\section{Assessing risk}

One of the recurring themes from the study related to the FOI officer's role in assessing whether a request should be recorded or treated any differently, particularly if it was deemed "contentious" in any way. This could include requests from the media that could result in coverage for the authority, requests from politicians or pressure groups, or requests that are seen as a "hot topic" in the local area (e.g., a local campaign or current media coverage). The FOI officer would proactively and often unaided, recognize such requests through their local general and political knowledge and appreciate the potential media coverage that could follow any release into the public domain of the information. One participant said:

"When we receive the request, one of the initial things that we do is we also look at the risk to the authority as well. So, we consider who it's coming from and whether it's got the potential to have any, I guess, adverse effects on the authority."

A second participant explained when they decide to send the request to their communications team for information.

"If we get any requests which are from the media or on any particularly hot topic.

You know, things in the local area that we know maybe of. If any concern, we will copy our corporate comms team in."

\section{Performance monitoring}

Many of the study participants run a centralized system and expect the devolved service areas to provide the requested information back to the central team who then release it to the requester. They spoke of the time they allow the service areas to respond back within. The United Kingdom Freedom of Information legislation requires, unless there is an extension to consider the public interest test as a result of some potential exemptions, that the information is released within 
20 working days from receipt of the valid request. Several participants initially pursue the request after 15 days, allowing a further 5 days for it to be compiled and released. Other timescales ranged from expecting the service area to respond in only 10 days through to letting them go up to the 20day deadline. Participants explained their processes as follows:

"Initially we say we need to respond back to me within the next 15 days and that just gives us enough time then to turn it round when we get the information back."

"On the spreadsheet we set up the reminder dates so we have a system of reminders two weeks before it's due, a week before it's due, and then three days before it's due. If we get to the day it's due, it's escalated to the director."

"So, we'll give them their five days and if we haven't heard back from them in five days, then my part time lady will be chasing that up and then, you know, every couple of days thereafter."

"We have a reminder automated reminder process through our IT system after 10 days. If we haven't gone into the back-office system and marked as complete, it would automatically send a reminder to the same team. Then we take manual action which will involve one of the officers ringing."

\section{Applying Exemptions}

The FOI officers are often instrumental in applying any exemptions and deciding what information should or should not be released by the authority in response to a request. It is unusual that this expertise and knowledge of complex exemptions is retained in the service areas that hold the information. In some authorities, their advice is considered and the service area makes the ultimate decision, but in most authorities, the FOI officer takes the ultimate decision on what to release. Participants said:

"I will have seen the information and thought that potentially this should have an exemption applied to it and then I'll discuss that with the Department."

"If we think immediately a request comes in, we might be looking at exemptions. We will say so."

"We will make the decision as to whether that information gets disclosed."

"They will then check whether the appropriate public interest test or prejudice test has been done with a good balance in the argument."

\section{Quality assurance}

The move to a centralized system by the majority of local authorities over the years seems to have been driven by the need for performance management and quality assurance. Participants 
were committed to ensuring the correct responses of good quality were released in compliance with the legislation, stating:

"We double check that every question has been answered and that the answer actually makes some sense and the answer is actually an answer to the question that's been asked. You'd be surprised how often it isn't. If they've used any hyperlinks that they actually work, and that if they've used acronyms we push back and say no, we don't use acronyms."

"Anything that goes in the public domain I want to make sure is consistent with everything else."

\section{Escalation}

The officers interviewed had no nervousness about escalating the outstanding FOI requests to more senior managers across the authority if the information was not forthcoming in a timely manner. Even where they were not senior managers, they had the confidence to escalate the delays up the management chain:

“.... and then we escalate that so if they don't respond to the first email we send an email that goes to their manager, and then there's a final one that goes to the director with responsibility for that area and all of that's before the 20 day deadline."

"If we get to the day it's due, it's escalated to the director."

"We'd escalate it to a more senior member of staff."

\section{Policy involvement}

The study wished to determine if the FOI officer had any involvement in or responsibility for the development of FOI policy. The results were split into almost two very distinct groups.

Firstly, several of the officers interviewed in the study acknowledged there had been little or no policy development in FOI for several years. There was an assumption that the law would be followed, guided by procedures and guidance, and staff would just "do it." Some study participants saw little need to update any policy if the main FOI legislation had not been updated. Few of these officers acknowledged the Protection of Freedoms Act 2012, or the revised Freedom of Information 2000 section 45 Code of Practice in 2018, which may have initiated policy reviews. Interesting comments referred to policies that no one reads, with one participant admitting even they had not read their organization's FOI policy. There was little buy-in from management in those authorities, with the FOI policy not being ratified at committees, full council, or in any management setting. Those participants agreed that there was little policy development and adoption as follows:

"It's just trundled along the way it has from day one." 
"We don't particularly develop... I mean obviously Freedom of Information was implemented and it's run... Most of the developments recently tend to be that should be driven by myself. Change tends to be driven by information officers and to some extent now the senior solicitor because she takes a more active interest in Freedom of Information.”

"I know one exists, I expect it is just the very kind of basic policy, this is what we're required to do this is how we do it. I doubt anyone's read it. I don't think I've ever read it."

"Where it's a council policy versus something that's guidance, the full Council has to sign it off, but only the data protection policy has gone to a full council and the records management policy has gone to full council sign off, not the FOI policy, so it is really guidance. We had a big work on that five or six years ago because there's too many saying that it was a policy when in reality policies could only be things that had been approved by the full Council. So, there's been a huge effort over the years to say look, what's guidance or our internal procedures versus a Council policy, so that's done through me. We try and do it every three years for our review period for all those policies, I have responsibility for data protection policy, as well as records management policy and the Freedom of Information guidance."

"That would be presuming that the Freedom of Information policy has changed and it hasn't."

"I may be the first person to read it for 15 years."

"I would say probably have procedures rather than a policy... I don't think we actually have ever had a policy... Freedom of Information is very important business stream. I can't see the reason for having a policy."

The second group, the remaining study participants, acknowledged their responsibility for proposing updates to policies and use local fora, networks and the Information Commissioner's Office's website as sources for information that informs them if a policy review is needed as follows:

"My task to review the policy every two years."

“I changed the system because I wasn't happy with how it was working. I write the policy. I decide how we work it as long as it follows the legislation."

"If there were any updates to legislation, so that that would be me, as the manager. I would update the Freedom of Information policy. I tend to look at it every year or every two years. I can't remember when I last did that, it will be on my log somewhere but I should get a ping when I'm due to look at the policy." 
"If it was a major change it would have to be agreed by committee, but the original Freedom of Information policy and information governance policies were agreed. So, if it's just minor updates, then that's just down to me."

"There is a policy, an internal policy. The published policy was reviewed not that long ago, it's down to me to do. It's exactly the same as complaints. With the Freedom of Information policy, I'd review it myself and change it. With the complaints policy I need to go to a committee, I need to go to the Council policy committee."

Several study participants downplayed or denied their input into any policy making. However, some are policy writers at unusually junior levels of the authority, and this is sometimes not reflected in job descriptions and job evaluation scoring.

In addition, when policy is presented to managers or committees for approval, there is often not the expertise at that level to appreciate if the policy is compliant with the legislation, placing all of the responsibility for the public authority's compliance onto the shoulders of the FOI officer proposing the changes.

"They're just looking for, is it in the right format and is it grammatically correct, really. I'm the expert on the content. So, actually making sure the content is legally correct would be up to me."

"I could say the moon is made of green cheese and probably chances are no one would notice that. I am responsible though. I do take it seriously!"

One study participant did assert that the FOI policy was checked by the senior information risk owner (SIRO), the executive board and finally a committee of elected members. Another refreshed the policy herself every three years and presents it to a corporate governance committee to get approval from elected members. A further two study participants refreshed the policy (one annually, one less regularly) but only needed sign off from their service directors after consulting their managers.

\section{Discussion}

One of the dominant themes emerging from the study participants' explanation of process is that a very similar standard procedure has embedded in the majority of local authorities taking part in this study, often at the behest of the FOI officers driving the process. That procedure involves a centralized process where requests are logged and overseen by a knowledgeable FOI officer, with elements of performance management and quality assurance applicable. Requests are then sent out to individual service areas, a hub and spoke system, with the information being returned to the central team to be checked and issued.

This is the typically adopted process despite local authorities' autonomy and many disparate cultures, sizes, and budgets. There are slight differences in some parts of the process in some authorities, for example, who signs off the release, or is it shared with the press office prior to release, but on the whole a similar regime of practice has emerged in English local authorities 
in response to the FOI officers finding the most efficient way to deal with the many FOI requests they receive.

In addition, many of the FOI officers are making similar key decisions regardless of their position in the staffing hierarchy. The FOI officers see themselves as the manager or coordinator of the process, and can often be seen as the lubricant of the procedure, making sure it becomes a well-oiled machine whenever there are obstacles and sticking points preventing the release of the information in a timely manner. They are also aware of current events and knowledgeable about current affairs and hot topics in their organization, recognizing, and flagging where expedient through risk assessment, requests that could be contentious, attract media attention or are political in nature. They also are responsible for policy but often downplay all of their responsibilities and deny their agency.

It is common for FOI officers in local authorities to be only adequately or poorly resourced, with many having inadequate administrative support, a lack of appropriate IT support and little or no adequate cover during periods of leave or sickness.

Many of those that are performing the FOI officer role are not recognized in title as undertaking the role; it is often seen as a secondary role or one that has been tagged onto their work, there is little recognition from senior management about how knowledgeable about law the role has to be (although as it has located more regularly in legal service department this perception is changing), and potential employees rarely even have to demonstrate any previous knowledge or experience in the field. Transferable skills are key to those that make a success of the role.

Despite English local authorities having the autonomy to decide how to manage the processing of FOI requests, the key findings of this study demonstrate that similar regimes of practice have evolved over the initial 15 years of the legislation. The key findings on the dominance of process have identified multiple and similar practices surrounding the implementation of the 2000 Act.

These practices are reproduced through on the job experience, FOI officers moving between councils, sharing ideas and best practice through word of mouth and communities of practice, and limited training courses by a select number of specialist companies in a vacuum of national training opportunities.

\section{Key areas of focus}

Multiple practices surrounding the implementation of the 2000 Act can be identified but recurring regimes of practice appear repeatedly, and predominantly in successful organizations as follows:

The People. Driving most successful FOI regimes is a passionate FOI officer. They can improve performance even when resources are scarce. They have the necessary skills and knowledge to drive improvement and, most importantly, the desire to do so. They learn on the job, often with no legal background, but often deny their abilities and agency.

The Place. Where does FOI sit within an organization? It's often moved around departments and no one seems quite sure where it should be. We see it in Legal Services, Customer Services, the Chief Executive's Office, Communications or IT. Where is the best fit and does it actually matter where it sits for it to be a success?

The Process. Over the years, many local authorities have moved from a decentralized model where individual service areas dealt with their own requests, with varying levels of compliance, to centralization of request management. The central performance management 
system not only helps with timeliness compliance but also quality of responses and correct application of exemptions.

The Technology. Different local authorities use different systems for managing requests. Ranging from a simple Excel spreadsheet to an all-singing, all-dancing specialist FOI service that automatically reminds people when responses are due and even redacts requests and publishes to a disclosure log, technology can definitely help manage the process and make it more efficient... if it is used well.

The Reporting. Freedom of Information is often overlooked whilst things are going well. Very often reports go up to senior management, but nothing comes down. There is little or no feedback, unless there is a problem. Regular reporting can, however, raise the profile of the service, get buy in from management, and highlight risks before it goes wrong.

So how are these regimes of practices reproduced throughout so many diverse and decentralized local authorities? The Communities of Practice. Some communities of practice have emerged through regional support groups or national mailing lists and online fora, usually driven by FOI officers themselves, but new FOI officers may struggle to find these networks, which can often be invaluable support to them.

\section{Recommendations}

This research generates lessons for successful practice and alternative modes of delivering FOI for those organizations performing poorly. The national regulator, the Information Commissioner's Office and relevant government departments (for example, The Ministry of Housing, Communities and Local Government or Cabinet Office) could use the outcomes from this research to issue national guidance, advice on best practice, and create a recognized national fora for FOI officers. Recognition of the professionalization of the FOI officer would be a welcome advance, placing it on an equal footing with data protection officers, with recognized qualifications introduced nationally.

As with many challenges facing local authorities, there is no central coordination and all of the councils are "re-inventing the wheel" in isolation. As the United Kingdom Freedom of Information Act applies equitably to all local authorities, the research could lead to the realization that every council needs an affordable logging system that is fit for purpose. Could an organization such as the Local Government Association, which represents local authorities, create such a system through existing IT systems that all local authorities could use?

It would be useful for researchers to have a central repository for local authority (and other public sectors) FOI performance statistics as there is for central government department. This is something that would be useful in all countries, regardless of the way local or state legislation works in that jurisdiction.

The research has also identified that there is a weakness in policy development due to the lack of central notification from the United Kingdom government to public sector organizations about any changes in FOI legislation or Code of Practice updates. Policy development and practice improvement often relies completely on the individual FOI officer being competent in horizon scanning and recognizing changes relevant to FOI law and practice. 


\section{Limitations}

The study did have some limitations, as the majority of participants were the more enthusiastic FOI officers and in the main represented the more successful organizations. Further research is needed with those organizations that perform poorly who did not engage with the research in order to establish if there are key aspects of the regimes of practice that lead to poorer performance. Further research is also needed with a more diverse set of stakeholders such as policymakers, senior managers, and bureaucrats to obtain a more holistic appraisal as to the regime of practice in an authority.

The resourcing of FOI requests could be compared between central government departments and local government. Local authorities receive many more requests but often only have one FOI officer. Comparing staffing and budgets against request numbers could also give an insight into regimes of practice and how to manage requests efficiently and effectively. All of the research carried out to date could be replicated in different jurisdictions across the world to investigate if similar regimes have proven successful elsewhere, or do different access to information regimes result in different regimes of practice and different bureaucracies.

Despite the limitations, this study provides a glimpse into the organizations structures and constraints that affect FOI administration at the local level, and potential areas for making it better. 


\section{References}

Amos, J., Dobias, J., Holsen S., and Worthy, B. (2008). Freedom of Information Act 2000: The third year. The experience of local authorities in England in 2007. The Constitution Unit, Department of Political Science, University College, London.

Blair, T. (2010). A journey: My political life. Penguin Random House.

Campaign for Freedom of Information. (1994, April). Addicted to secrecy, lies, and distortion. https://www.cfoi.org.uk/1994/04/addicted-to-secrecy-lies-and-distortion/

Campaign for Freedom of Information. (1996, May 25). Speech by the Rt.Hon. Tony Blair MP, leader of the Labour Party at the Campaign for Freedom of Information's annual awards ceremony. https://www.cfoi.org.uk/1996/05/speech-by-the-rt-hon-tony-blair-mp-leaderof-the-labour-party-at-the-campaign-for-freedom-of-informations-annual-awardsceremony-25-march-1996

Campaign for Freedom of Information. (2001, November 13). Double blow to freedom of information. https://www.cfoi.org.uk/2001/11/double-blow-to-freedom-of-information/

Committee on the Civil Service. (1968, January 1). Civil service: Report of the committee, 196668. V. 1 (Command 3638). https://docs.google.com/document/d/1ANxPtL_7QUg4adwzU28uAVOVReR_VCpM7ea8ukt9ug/edit

Constitution Unit. (2011, November). FOIA 2000 and local government in 2010: The experience of local authorities in England. https://www.ucl.ac.uk/constitution-unit/sites/constitutionunit/files/2010-foi-officers-survey.pdf

Environmental Information Regulations.

(1992). http://www.legislation.gov.uk/uksi/1992/3240/contents/made

Holsen, S., \& Worthy, B. (2010). Open government at the local level in England: FoI implementation from 2005 to 2008, Routledge, 27-41.

Independent Commission on Freedom of Information. (2017, November). Freedom of information code of practice: Consultation on revisions to the FOI Code of Practice. https://assets.publishing.service.gov.uk/government/uploads/system/uploads/attachment_ data/file/659607/FOI_Code_of_Practice_Consultation_Document.pdf

Independent Commission on Freedom of Information. (2018, July 4). Freedom of information code of practice. https://assets.publishing.service.gov.uk/government/uploads/system/uploads/attachment_ data/file/744071/CoP_FOI_Code_of_Practice_-_Minor_Amendments_20180926_.pdf

Labour Party Manifesto. (1974). http://www.labourmanifesto.com/1974/oct/1974-oct-labourmanifesto.shtml

Lister, I. (1988, July). Opening up the town halls: the Local Government (Access to Information) Act 1985. London Review of Public Administration, 19.

Local Government Act of 1972 (1972). http://www.legislation.gov.uk/ukpga/1972/70

mySociety. (2021, April). Reforming freedom of information. https://research.mysociety.org/html/reforming-foi/\#top

Parsons, A., \& Rumbul, R. (2019, April). Freedom of information in local government. mySociety. https://research.mysociety.org/media/outputs/mysociety-local-governmentfoi_1Fa9d6X.pdf

Public Records Act of 1967. (1967). http://www.legislation.gov.uk/ukpga/1967/44/enacted

Scottish Information Commissioner. (2021). Statistics reports. https://stats.itspublicknowledge.info 
Secrets Newspaper. (1984). http://www.cfoi.org.uk/pdf/SecretsNewspaperNo1.pdf

Shepherd, E., Stevenson, A., \& Flinn, A. (2010). Information governance, records management, and freedom of information: A study of local government authorities in England. Government Information Quarterly, 27(4), 337-345.

Steele, J. (1995). Public access to information an evaluation of the local government (Access to Information) Act 1985. Local Government Research Programme, Policy Studies Institute, Department of the Environment.

Wagenaar, H. (2004). "Knowing" the rules: Administrative work as practice. Public Administration Review, 64(6), 643-655.

Worthy, B. (2013). Some are more open than others: Comparing the impact of the Freedom of Information Act 2000 on local and central government in the UK. Journal of Comparative Policy Analysis: Research and Practice, 15(5), 395-414.

Worthy, B., Amos, J., Hazell, R., \& Bourke, B. (2011). Town hall transparency? The impact of the Freedom of Information Act 2000 on local government in England. The Constitution Unit, Department of Political Science, University College, London.

Your Right to Know. (1997). The government's proposals for a Freedom of Information Act. https://www.gov.uk/government/uploads/system/uploads/attachment_data/file/272048/38 18.pdf 


\title{
Appendices
}

\author{
Appendix A. Participants' portraits
}

\section{Participant 1}

Participant 1 works as an Information Officer located in the Legal Services department of a district council. They have day-to-day dealings with Freedom of Information and Environmental Information Regulations requests and also deals with issues relating to the Data Protection Act. They see the request process through from the receiving of the request through to the release of the information, as well as dealing with internal reviews and correspondence from the Information Commissioner's Office.

\section{Participant 2}

The second participant is a Data Protection Officer at a borough council whose role involves managing data protection, Freedom of Information, Environmental Information Regulations and the Regulation of Investigatory Powers Act for their local authority. Coming from a secretarial background, and subsequently involved in performance management, they inherited the responsibility for Freedom of Information when the then current incumbent in Legal Services was due to retire, over ten years ago.

\section{Participant 3}

Participant 3 is a Data Protection Officer and Corporate Information Governance Officer at a unitary authority, managing the information governance team. They are responsible for all information rights requests under the Data Protection Act, Freedom of Information and Environmental Information Regulations, and also give advice to the rest of the authority and local schools. Participant 3 also acts as the data protection officer for a local partnership related to the local authority.

\section{Participant 4}

The fourth participant is the Information Governance Manager at a large county council who has managed a transparency team who handle subject access requests under the Data Protection Act 2018, and the statutory requests team that focus on Freedom of Information and Environmental Information Regulations requests for the last five years. They also manage a traded service providing services to schools.

\section{Participant 5}

Participant 5 is an Information Governance Officer at a borough council with responsibility for Freedom of Information and all data protection related matters. Their previous background was in organisational development, equalities and performance management but in addition they dealt with Freedom of Information requests.

\section{Participant 6}

Participant 6 is a former civil servant who took on the Information Governance Manager role for a district council. They are also the local authority's Data Protection Officer. Their previous role in the civil service saw them responsible for answering many Freedom of Information requests 
from about 2007 onwards so they were familiar with the legislation when applying for their current role.

\section{Participant 7}

The seventh participant Data Protection Officer and Corporate Compliance Manager who manages the small team of 1.5 members of staff that deal regularly with the Freedom of Information requests and other information rights requests. They themselves spent time being the Freedom of Information officer for just over two years before taking on the manager role.

\section{Participant 8}

Participant 8 is an Information Governance Lawyer at a County Council. They were mainly aware and interested in data protection law and did not have experience in Freedom of Information originally. They advise the local authority, as well as other public bodies within the county, in relation to information requests.

\section{Participant 9}

The ninth participant is an Information and Records Manager for a county council with responsibility for Freedom of Information and data protection as well as data breaches and records management for the Council and a strategic overview for record archives. They have held their current post since 2009 but they have been involved in Freedom of Information since its inception. They took on the management role when the two councils merged.

\section{Participant 10}

Participant 10 is an Information Governance Officer and the Data Protection Officer at a borough council. They are responsible for Freedom of Information and some degree of cybersecurity matters, as well as a data protection which includes due diligence and general information compliance. They have been in that role for four years but have been working in the Freedom of Information and data protection field for over ten years after the work being added to their original job role.

\section{Participant 11}

The eleventh participant is an Information Governance Officer at a borough council. They advise on Freedom of Information when colleagues need to apply exemptions, and on data protection matters. They have been working in the Freedom of Information area for the last 15 years. Their background was in committee administration but they moved to help with the implementation of Freedom of Information.

\section{Participant 12}

Participant 12 is a Data Protection Officer at a borough council who oversees two members of staff, quality assures the Freedom of Information responses and gives advice on applying exemptions. They have been in role since implementing Freedom of Information whilst they were a Records Officer.

\section{Participant 13}

Participant 13 brings a more unique perspective to Freedom of Information in local authorities as a freelance data protection and Freedom of Information consultant. They often go into a local 
authority on a fixed term contract to improve one aspect of the process but identify other issues whilst there.

\section{Participant 14}

Participant 14 is a Senior Complaints Practitioner at a county council. They are the senior practitioner and manage Freedom of Information requests, subject access requests, and Police disclosure requests. They have been in post for approximately ten years, previously working just on complaints. The Freedom of Information part of the role was placed alongside the complaints work when it was recognised central oversight of Freedom of Information was needed.

\section{Participant 15}

Participant 15 has the title of Senior Information Officer in Freedom of Information and works in a Unitary authority. They have worked in the area of Freedom of Information for the past six years and were previously in various different role at the authority which was at risk due to funding issues. They deal with all aspects of Freedom of Information.

\section{Participant 16}

Participant 16 has been an Information Governance Manager in a District Council for the last three years. They ended up in the team after a restructure within the authority due to lack of budget, and more resources were required in the information governance area to ready the council for the General Data Protection Regulation. Their existing skills and knowledge were deemed a good fit. They support the main Freedom of Information officer on requests.

\section{Participant 17}

The final participant is an Information Governance and Risk Manager in a unitary Council. They manage the day-to-day operations of the team that deals with Freedom of Information, data protection and information security, and deal with appeals. They have been in their current role since October 2016, but have been working in the information governance field in local authorities since the early $2000 \mathrm{~s}$. 
Appendix B. Coding

Accountability

Advice

Applicant Blind

Applying exemptions

Assign the request

Authorization process

case management system

Chief Executive

Code of Practice

Compliance rates

Contentious or sensitive requests

Council teams

Dark art

data protection

day-to-day

Decision making by FOI officer

Disclosure log

drafting responses

EIRs

Elected members

Escalation process

Experience \& knowledge

FOI

FOI Officers VIEWS on FOI

Follow up or chase

Horizon scanning

ICO

ICO complaints

Improvement

Information Governance

Information officer

Internal review 
Legal Service

Local Groups

Logging the request

Management involvement

Media requests

Members of parliament

Monitoring Officer

Other roles of the FOI officer

Policy development

Political requests

Previous profession

Prioritization

Proactive publication

Public Interest Test

Qualifications

Reason for working in FOI

Release of response

Reporting of data

Reporting structure

Request arrival

Requester identity

Resourcing

Return to central team

Risk assessment

Template responses

Time for responses

Time in FOI

Training

Type of requester

Unique reference number

WhatDoTheyKnow.com 